\title{
Memoria e Historiografía en torno a las Instrucciones Orientales de 1813
}

DOI

http://dx.doi.org/10.1590/2236-463320150906

Memory and Historiography around the Artigas's Instructions of 1813

\author{
Ana Ribeiro \\ Profesora en la Universidad Católica \\ del Uruguay (UCUDAL - Montevideo \\ / Uruguay) \\ e-mail: historiadoraribeiro@gmail.com

\section{Gerardo Caetano} \\ Profesor en la Universidad de la \\ República (UDELAR - Montevideo / \\ Uruguay) \\ e-mail: gcaetano50@gmail.com
}

\section{Resumen}

En el presente artículo, y a propósito del Bicentenario de las "Instrucciones" artiguistas de 1813, los autores realizan una revisión historiográfica de las interpretaciones y revisiones a que ha dado lugar este documento considerado fundamental en el contexto de la revolución oriental, pero también una inspiración perdurable de la democracia uruguaya en la "larga duración". Esta revisión historiográfica permite ejemplificar el pleito de sentidos y los factores políticos que inciden en la configuración de documentos de este tipo, considerados fundacionales en el marco de una historia nacional y nacionalista. A través de ella se repasan los autores, los contextos y los periodos en que tuvieron lugar las principales resignificaciones históricas e historiográficas del documento artiguista "Instrucciones del año XIII".

\section{Abstract \\ In this article and on porpuse of bicentennial of the Artigas's Instructions in 1813, the authors realize a historiographical review of the interpretations and revisions product of this document, considered fundamental in the context of the Eastern Revolution, but also as enduring inspiration of Uruguayan democracy in the "long term». This historiographical review allows us to illustrate lawsuit senses and political factors that affect the configuration of such foundational documents in the context of a national and nationalist history. Through this article the authors, contexts and periods when the major historical and historiographical reinterpretations of Artigas's document "Instructions of XIII" took place are reviewed. \\ Palabras-clave \\ Artigas, revolución independentista, historiografía, Uruguay, Bicentenario \\ Keywords \\ Artigas, Independence Revolution, historiography, Uruguay, Bicentennial}


1-El Bicentenario de las Instrucciones del año XIII y el pleito de sus sentidos En 2013 el Uruguay celebró, festejó y conmemoró el bicentenario de las Instrucciones del año XIII, firmadas por Artigas y portadoras de conceptos políticos que causaron en su tiempo gran inquietud y controversia en el escenario rioplatense.

Las formas de conmemoración a lo largo de la historia uruguaya de estas Instrucciones artiguistas de 1813 no han sido homogéneas. Luego de superados los bloqueos del olvido y de la "leyenda negra" antiartiguista, desde las últimas décadas del siglo xix hasta hoy, cada generación de uruguayos encontró su manera específica de recordar y proyectar el legado político del artiguismo, desde las preguntas e interpelaciones cambiantes de cada presente. El cómo conmemorar, además de interpelar al oficio de los historiadores y a los rumbos siempre debatidos del campo historiográfico, forma parte de las controversias políticas, de cara a las exigencias de la contemporaneidad. Las sociedades, en particular aquellas que -como la sociedad uruguaya- reivindican una convivencia democrática, requieren fundar sus convicciones cívicas tanto desde la inspiración del pasado como desde la interpelación del futuro a construir, conjugan tradiciones y utopias. $Y$ en esa tensión persistente, las conmemoraciones de los hitos 0 documentos que las sociedades han definido como "fundacionales" resultan propicias tanto para la acción de "rememorar" -"traer a la memoria"-, como para la indagatoria acerca de las continuidades y novedades sobre el cómo lo hacemos.

Esta última exigencia de relacionar las raíces con el futuro, supone el registro de distintas formas de relato y representación del acontecimiento a conmemorar; la forja consciente y creativa de las marcas contemporáneas de la memoria; la asunción plena de las tensiones creativas del recordar/intervenir/construir, así como de la dialéctica entre pasado y futuro; el diseño de una conmemoración que no puede desentenderse de las significaciones del eje del territorio (lo "iberoamericano", lo "hispanoamericano", lo "español americano", lo "latinoamericano", lo "americano", lo "argentino oriental", lo "oriental", lo "uruguayo", las visiones desde Montevideo y de los diversos "interiores", etc.); los aportes a menudo difíciles -en ocasiones radicalmente desencontrados- del diálogo intergeneracional; la celebración simultánea de la diversidad de identidades e historias, que alejen el atajo infértil de las conmemoraciones homogeneizadoras y previsibles, entre otros muchos posibles enfoques.

La relación entre las ideas de pasado y futuro como tema central de la conciencia histórica y de la política democrática, ocupan un lugar especialmente relevante en las reflexiones teóricas de la Historia, la Filosofía Política y la Prospectiva, configurando una temática tan clásica como de fuerte vigencia contemporánea. Una recorrida por la historia latinoamericana contemporánea nos devolvería una imagen afinada de cuánto implica indagar en profundidad respecto a estas elaboraciones. En este marco, las conmemoraciones de los diversos Bicentenarios de las revoluciones hispanoamericanas, más allá de sus múltiples debates y de los pliegues contrastantes de sus escenarios celebratorios, se constituyen en coyuntura propicia para renovar ese cruce tradicional entre balances y prospectos.

Toda conmemoración, en particular sobre un hito como el de las Instrucciones artiguistas de 1813, es el escenario de un debate de sentidos, en el que cobran vigor los conflictos por los usos públicos de la memoria y sus complejos vínculos con la reconstrucción histórica del pasado. Esta faena 

inaugurar el Congreso de Tres Cruces. El 04 de abril de 1813. Archivo Artigas. Tomo XI, Comisión Nacional Archivo Artigas, Ed. Monteverde, Montevideo, 1974, p.68. no es monopolio de los historiadores, aun cuando estos deban aportar (y recordar) las rigurosas reglas del oficio, frecuentemente desafiadas por los usos políticos y/o populares de la Historia. En esos contextos, el trabajo de los historiadores no se construye desde un "limbo" abstracto y trascendente, sino que se produce en el marco mismo de las conmemoraciones, en las que sin duda participan e interactúan con una multiplicidad de actores. Recordar esto siempre es necesario pues, entre otras cosas, aleja a la historiografía de la infértil pretensión de la administración de los "discursos de la verdad" sobre el pasado.

Más allá del contexto local, las Instrucciones de 1813 emergen como un pronunciamiento político e ideológico significativo en el marco de las revoluciones hispanoamericanas. En más de un sentido, constituyen una de las definiciones políticas más relevantes del ciclo artiguista, uno de los ejemplos máximos (junto con la primera etapa de la revolución mexicana de Hidalgo y Morelos) de una revolución popular luego derrotada. Esas Instrucciones perfilan una orientación política e ideológica radical para su tiempo y sintetizan el imaginario político que sustentaba por entonces el concepto de soberanía particular de los pueblos orientales: Independencia, República y Confederación.

Aunque no vuelvan a producirse los intensos debates que marcaron al continente hace un siglo, algunas condiciones históricas actuales de Latinoamérica pueden propiciar revisiones fermentales. En los Centenarios se demandó y afianzó un relato de los "orígenes" que apuntalara los procesos de afirmación nacional de los aun jóvenes Estados americanos. En los Bicentenarios las demandas son otras y convierten el documento "Instrucciones del año XIII" en un texto polivalente, solo abarcable en clave historiográfica.

\section{2- Historia e historiografía del documento}

El mito fundacional de la "nueva nación" fue alimentado en la revolución oriental desde sus inicios. Basta recordar el inequívoco párrafo de la "Oración Inaugural" del 5 de abril, en la apertura del Congreso del cual emanaron las Instrucciones: "Nuestra historia es la de los héroes. El carácter constante y sostenido que hemos ostentado en los diferentes lances que ocurrieron anunció al mundo la época de la grandeza. Sus monumentos majestuosos se hacen conocer desde los muros de nuestra ciudad hasta las márgenes del Paraná. Cenizas y ruina, sangre y desolación, ved ahí el cuadro de la Banda Oriental y el precio costoso de su regeneración. Pero ella es pueblo libre"1. Autorepresentación de gran fuerza, en un Río de la Plata casi sin memoria virreinal, en el que se habían vivido hacía poco tiempo episodios de autodefensa como los que desataron las rechazadas invasiones inglesas.

Luego, cerrado el largo proceso que culminó con la independencia uruguaya en 1828-30, comenzaron los pleitos por el relato de lo acontecido. La historiografía uruguaya nació mucho después que el pais y se inauguró revisando la historiografía argentina, que rodeó a Artigas de lo que luego se denominaría la "leyenda negra antiartiguista". Para el relato uruguayo de la nación, el país había sido preanunciado por la sola existencia del río, para nacer ineluctablemente, defendido de forma unánime por todos sus habitantes. Esa tesis fue gestada en paralelo a la construcción del Estado nación, y sus autores y obras fueron producto de un doble desprendimiento: respecto a España y respecto a Buenos Aires. La amenaza 
VEDIA Y MITRE, Mariano de. El manuscrito de Mitre sobre Artigas. Buenos Aires: Libreria y editorial "La Facultad", Bernabé y Cía, 1937. p.126. de una reconquista por parte de la Corona española llegó a su fin alrededor de 1820; en cambio, las Provincias Unidas del Río de la Plata siguieron influyendo y participando en la política uruguaya hasta muy avanzado el siglo XIX. Por eso los mayores esfuerzos historiográficos se concentraron de cara a Argentina, en una pugna entre la "leyenda negra" y la "dorada", que culminó exaltando a Artigas como héroe fundador del Uruguay. Esta pugna, a la que no le faltaron ribetes políticos, resultó también inseparable del destino de las Instrucciones de 1813.

Las primeras formas historiográficas que recogieron el documento y su momento histórico fueron las crónicas y efemérides. El Diario de Francisco Acuña de Figueroa, escrito desde el Montevideo amurallado y perfeccionado hasta su publicación en 1844 , solo ofrecía datos externos sobre su contexto de origen, ya que su observador miraba desde lejos a los revolucionarios acampados a las afueras de la ciudad: que el Congreso se postergó por lluvia; que los sitiadores balearon fuertemente a Montevideo ese día; que el 5 de abril cayó en lunes y que mientras el Congreso iniciaba sus sesiones, cinco sitiadores desertaron y se pasaron al Montevideo sitiado; que el miércoles se balearon y bombardearon duramente, cayendo granadas dentro del recinto amurallado. Para el jueves 8 los detalles fueron mayores: en formación, desfilaron los granaderos, los cuerpos de artillería y los Dragones "con aparato solemnizan/la Jura del Congreso o Asamblea", mientras Artigas - que ya había entregado a la Asamblea los "Ocho puntos" por los cuales condicionaba la obediencia que la Asamblea General Constituyente le reclamaba- prestaba su juramento frente al general Rondeau. El martes 13, la noticia no fueron las Instrucciones entregadas ese día a los diputados electos, sino la obra benéfica que hacía el lego Ascalza, dentro de la hambrienta Montevideo sitiada.

Otra pluma de la época fue la del inglés J. P. Robertson, que visitó a Artigas en Purificación, en el año 1815. La imagen del sacerdote-secretario, sentado ante una mesa de pino mientras Artigas le dictaba, fue tan plástica que Pedro Blanes Viale la inmortalizó en las primeras décadas del siglo xx en su cuadro Artigas dictando a su secretario Monterroso, cuadro al que, por error, se ha presentado muchas veces como Artigas dictando las Instrucciones del año XIII. Todas las demás crónicas de la época retratan al Artigas guerrero y a su entorno, sin espacio para pensamiento ni labor jurídico-normativa que pudiera adjudicarse al caudillo, nombre que estigmatizaba el origen espúreo de su poder militar. La documentación, riquísima y actualmente compilada en los casi cuarenta tomos del Archivo Artigas, no se publicaba y corría por vías del secreto o con el sello de "reservada". Si bien en su momento las Instrucciones fueron muy mentadas por su impacto en la Asamblea General Constituyente, a partir de 1820, cuando llegó a su fin la experiencia política del artiguismo, cayeron en el olvido.

La historiografía mitrista concentró adjetivos en torno al caudillo derrotado: "perjuro, ingrato, insensible a las desgracias de sus hermanos y al interés sagrado de la patria", escribió Mitre². El Ensayo de Historia Civil del Dean Gregorio Funes (1817), el folleto de Cavia (1818), las Memorias del General Miller (1829) y los apuntes que le proporcionó el general Vedia (1841) fueron la base sobre la cual Mitre emprendió un libro sobre Artigas (que quedó inconcluso), en cuyo borrador anotó: "Artigas fue el apóstol armado de la federación, como Moreno fue el apóstol pacífico. El sistema federal de Artigas es la federación de los tiempos primitivos en q. ${ }^{e}$ la fuerza 
Apuntes de Bartolomé Mitre para una obra sobre Artigas, PIVEL DEVOTO, Juan. De a leyenda negra al culto artiguista. Montevideo: Biblioteca Artigas, Colección de Clásicos Uruguayos Vol.171, 2004. p.223.

4

EL DEFENSOR DE LA INDEPENDENCIA

AMERICANA. Miguelete, n.193, p.3, columnas 2 y 3, febrero 19 de 1847

5

DECRETO del 24 de mayo de 1849. El Defensor de la Independencia Americana, Montevideo (Gobierno del Cerrito) n ${ }^{\circ} .400$, p.2, columna 2, mayo 27 de 1849 .

6

Tomado del Diario de Francisco Solano Antuña, citado en MAGARIÑOS DE MELLO, Mateo J. El gobierno del Cerrito: colección de documentos oficiales emanados de los poderes del gobierno presidido por el Brigadier General D. Manuel Oribe 1843-1851. Montevideo: Poder Ejecutivo, Leyes, Decretos, Resoluciones y Circulares, 1948. Tomo I, p.202.

7

RAMíREZ, Carlos María. Artigas. Con Introducción del ministro D. Justino Zabala Muniz y prólogo de Luis Bonavita. Montevideo: Colección de Clásicos Uruguayos, 1985. v.1, p.381-382.

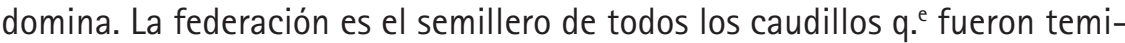
dos, desde Artigas hasta Rosas y Urquiza"3.

El grupo unitario presente en Montevideo durante la Guerra Grande, de gran actividad intelectual, recibió y difundió el Facundo de Sarmiento y el recién publicado Ensayo histórico de los suizos Rengger y Longchamps, en el que se hablaba de Artigas en su vejez como el "padre de los pobres" en su exilio paraguayo. Sarmiento identificó a las montoneras con la barbarie y le dio a Artigas paternidad respecto a Rosas, su heredero. Historiando la montonera, Mitre insistió en 1846, calificando a Artigas como "idolo de la multitud ignorante".

Fue en ese momento y en ese entorno que aparecieron las primeras alusiones reivindicatorias, no como hombre de pensamiento político, sino como guerrero de la independencia. Fueron las intervenciones europeas y los enfrentamientos entre caudillos y sectores doctorales los que motivaron a ambos bandos en lucha a invocarlo. Melchor Pacheco y Obes lo halagó desde su postura, contraria a las intervenciones europeas, como un poder gaucho sostenido por "chuzas". Cuando Fructuoso Rivera, que fuera el primer presidente del Uruguay independiente, aludió severamente a los sucesos "del tiempo de Artigas y de los males que [entonces] la República sufrió", la crítica del diario oribista El Defensor de la Independencia americana no se hizo esperar. Lo de Rivera -escribieron- era una "grave injuria á este Gefe esclarecido, digno del respeto y consideraciones de sus conciudadanos, por su acendrado patriotismo, y por los esfuerzos heroicos que hizo, apesar de los escasos recursos de que disponia, para liberar á la Patria de la dominacion de los extrangeros [...]"4.

Esa exaltación americanista de Artigas hizo que, por decreto de Oribe, se bautizara la calle principal de la villa Restauración con el nombre "General Artigas". También llevó el nombre de Artigas una batería de la viIla, "en homenaje al General y por hallarse situada a donde estuvo en 1812 y 13 el reducto de Artigas"6. Fue la única e indirecta mención al fermental año 1813, pero no por su labor política sino -una vez más- por la condición de guerrero de un hombre cuya memoria tempranamente comenzaba a ser disputada por las dos incipientes comunidades políticas en lucha: el Partido Colorado de Fructuoso Rivera, el Blanco de Manuel Oribe. Carlos María Ramírez lo dijo por entonces con claridad:

el General Oribe siguió el ejemplo del General Rivera, aspirando a prestigiar su causa con la presencia del Caudillo histórico en el campo sitiador. Aunque sus esfuerzos se estrellaron en una resistencia idéntica, quedó bien definido desde entonces el paralelismo con que los dos grandes partidos orientales querian operar la completa rehabilitación del general Artigas.

Oribe intentó incluso la repatriación "del viejo y glorioso Caudillo"7. Luego de muerto Artigas en 1850, el 5 de febrero de 1851 El porvenir de Montevideo reclamó el retorno de sus restos al país, por ser Artigas alguien que "consagró su vida por su independencia y libertad como su primer guerrero". Cuando sus restos fueron efectivamente trasladados desde Paraguay, en el documento oficial que consagró los homenajes tributados (con fecha 20 de noviembre de 1856) se lo nombró "Fundador de la Nacionalidad". Su cadáver erró durante algunos años. Fue sepultado junto al pedestal de un Cristo tallado en piedra, en el Cementerio Central. Tres años más tarde se lo instaló en forma provisoria en el Panteón de la familia del presidente Pereira. En 1864 volvió a trasladárselo a un panteón al que luego denominarian "Panteón Nacional". 
PELLIZA, Mariano. Dorrego en la historia de los Partidos Unitario y Federal. Buenos Aires: Carlos Casavalle Editor, Imprenta y libreria de Mayo, 1878. p.9.

Cfr. PUSINERI SCALA, Carlos Alberto. Archivo Nacional de Asunción. Asunción: Anuario de la Academia Paraguaya de la Historia, vol.XXV, 1988.

10 PELLIZA, Mariano. 0p. Cit., p.80.

11

Ibidem, p.160.
El héroe - páter tenía ya un lugar, pero las Instrucciones seguian olvidadas, situación que se prolongó hasta que se publicaron por primera vez. Lo hizo el historiador argentino Mariano Pelliza, quien las incluyó en su libro sobre Dorrego, en 1878. Pelliza sabía que Artigas había sido "la piedra del escándalo" en el año 1813, que sus diputados habian sido rechazados y que "la censura más animosa" fue lanzada contra él:

\footnotetext{
¿Qué habia hecho Artigas? ¿Las Instrucciones que dio a los diputados [...] eran criminales? ¿Dónde existen esas instrucciones, nos dijimos? No estaban publicadas y el misterio aparecía indescifrable; no obstante, á fuerza de investigar y de inquirir las encontramos. Artigas habialas pasado en copia al doctor Francia dictador del Paraguay, y del archivo privado de este vinieron á nuestras manos. ${ }^{8}$
}

Las Instrucciones eran célebres, pero desconocidas; había mentas de ellas, pero no se sabía su contenido exacto.

\section{3- Las Instrucciones como documento édito}

Pelliza llegó a ellas por un curioso camino: el saqueo documental sufrido por Paraguay como consecuencia de la Guerra de la Triple Alianza. Cuando Luque fue nombrada segunda capital de la República de Paraguay en 1868, todo el Archivo paraguayo se trasladó en carretas hacia esa ciudad; poco después pasó a Piribebuy, tercera capital y lugar donde el archivo cayó en poder de los Aliados, que se repartieron sus casi 50.000 documentos. Héctor Francisco Decoud, en su libro Sobre los escombros de la guerra, recuerda que durante su estadía en Buenos Aires, en el año 1886, "le ofrecieron varios documentos, asi como planos de algunas zonas del territorio nacional, con sus informes respectivos mandados levantar por el Gobierno de Don Carlos Antonio López en 1857, habiendo adquirido todo el Block"'.

Además de incluir en su libro el texto de las Instrucciones que había encontrado, texto fechado el 13 de abril y con firma de Artigas, Pelliza señalaba que el contenido de las mismas fue el factor determinante para el rechazo de los diputados orientales: "el verdadero motivo eran las instrucciones, que les imponian como primer exigencia la declaratoria de emancipación absoluta de la España; siguiéndose inmediatamente la constitución del país por el sistema de confederación [...]". Eran incompatibles con el rol moderador de la Asamblea, que si bien no cumplió su cometido básico de ser constituyente, en opinión de Pelliza dotó al país de un "código político".

Pelliza señaló también que, aunque el "apóstol" del federalismo fue Mariano Moreno, Artigas fue el primero en levantar la bandera de la federación en sus "célebres instrucciones", de las que dice: "sin hacer la apología de Artigas debemos consignar en elogio de aquel documento que lleva su firma autógrafa, que una definición más acertada y completa del sistema federal democrático no puede concebirse en aquellos tiempos de rudo aprendizaje marcial [...]"10. No queda claro si Pelliza le daba al concepto democracia el significado liberal que luego se generalizó, o el de régimen directo y cuasi jacobino que tenía en sobre todo en la primera mitad del XIX, como herencia de la antigüedad clásica, pero sí fue preciso al reivindicar el "federalismo" de las montoneras. Contrariando a Sarmiento, afirmó: "fue malo Artigas, pero no eterno, y no era discreto atacar un sistema político a todas luces conveniente, porque existieran dos o tres caudillos que al fin se alzaron con las provincias [...]"11.

El otro rasgo sobresaliente que Pelliza les señaló a las Instrucciones (rasgo complementario de toda la idea confederal) fue la audaz locación 
BERRA, Francisco. Bosquejo histórico de la República Oriental del Uruguay. Montevideo: Librería Argentina de Francisco lbarra - Editor, 1881. p.149 y ss. de la capital, que necesariamente debería estar situada fuera de Buenos Aires. Esa exigencia era un reflejo de "la esperanza [de Artigas] de llevar á Montevideo al asiento del gobierno nacional"12.

Este atemperado juicio de Pelliza no incidió en Francisco Berra (argentino que vivía y escribía en Uruguay), quien en 1881 publicó su Bosquejo histórico de la República Oriental del Uruguay, una obra documentada y bien escrita que manifestó duras críticas a la modalidad caudillesca de poder. Su alusión a las Instrucciones era indirecta, pero inequívoca:

Se ve que no gobernaba Artigas con ninguna de las formas de gobierno adoptadas hasta entonces por los pueblos civilizados. Su voluntad, variable a cada momento, era el todo: poder legislativo, poder judicial, poder ejecutivo. Habia leyes, pero Artigas las desconocía. Había gobernadores y cabildos, pero sin autoridad propia, meros ejecutores de las órdenes que recibian del Jefe. Había pueblo, y se invocaba su voluntad en circunstancias dadas; pero ese pueblo carecía de significación política, porque estaba absolutamente sometido al poder de su caudillo [...].

Ni demócrata ni monárquico, ni para gobernar la Banda Oriental ni para hacerlo con Corrientes o Entre Ríos, ni en lo civil ni en lo militar, dice Berra. "No había sombra de democracia ó de figura republicana; no había ni aun un remedo de las formas monárquicas: el gobierno de Artigas presentaba el tipo de la autocracia más acabadamente unipersonal y absoluta; era la negación de todo organismo político, por más embrionario que se le conciba". El libro de Berra fue durante años el texto fundamental en la enseñanza uruguaya, mejorado y ampliado en cuatro ediciones, la última de 1895, extendido de 462 a 720 páginas. A lo largo de esas ediciones no cambió su juicio adverso sobre Artigas ni su descreimiento respecto a una independencia que "se produjo sin que tuviera una causa determinante en los precedentes históricos, ni en el sentimiento popular, ni aun en la voluntad accidental de la Provincia" 13.

La reivindicación de las Instrucciones y su autor comenzaron de manera más enfática hacia 1880, promovidas desde el Estado uruguayo y a través de una serie de obras didácticas que procuraron dotar de emocionalidad al "panteón patrio". Los nombres de Carlos María Ramírez y Clemente Fregeiro alimentaron las polémicas y los acopios documentales sobre el artiguismo y el proceso de la independencia, mientras Francisco Bauzá escribía La historia de la dominación española en el Uruguay, que se publicó en varios tomos, entre 1880 y 1882 . Bauzá reivindicaría un Artigas "que es el primero que proclama la independencia". Sintetizaria sus ideas -las que calificó de grandes- en tres: la independencia, el sistema republicano y el respeto al Derecho de Gentes. Bauzá destacó la idea de República en su acepción de forma de gobierno opuesta a monarquía, pero no en la significación política de proactividad cívica (popular, participativa, radical) que formulara el artiguismo. Apropiarse de las Instrucciones requería, entre otros deslizamientos conceptuales, esa transmutación de los sentidos dados a la voz república.

El Ateneo de Montevideo y la prensa local fueron escenarios de encendidas polémicas sobre Artigas y su ciclo revolucionario, en años de militarismo primero, de civilismo después. En 1882, Carlos María Ramírez hizo una encendida defensa de las Instrucciones: fue el primer autor uruguayo en publicarlas. Fueron -dijo- una revolución dentro de la revolución: 
14

RAMíREZ, Carlos María. Juicio Crítico del Bosquejo Histórico de la República Oriental del Uruguay por el Dr. D. Francisco A. Berra. Montevideo: Imp. El Porvenir, 1882. p.123.

15

Ese culto fuertemente personalizado atravesaría todos los gobiernos y partidos políticos, culminando en el pasado reciente con la controvertida propuesta del entonces presidente Tabaré Vázquez de jerarquizar el 19 de junio como la gran celebración nacional, que incorporaría de alli en adelante el agregado de configurar la fecha del Nunca más (vinculada a las muertes y desapariciones durante la dictadura militar) : una extraña -y finalmente fallidaasociación simbólica entre el nacimiento del "hombre más preclaro" y la negación de todo lo fallido y erróneo de la historia nacional.

16

ZORRILLA DE SAN MARTIN, Juan. La epopeya de Artigas: historia de los tiempos heroicos de la República Oriental del Uruguay. Montevideo: Talleres Gráficos Barreiro y Ramos, 1910. p.179.

17

MAESO, Justo. El General Artigas y su época: apuntes documentados para la Historia Oriental. Montevideo: Imprenta Oriental de Peña y Roustan Maeso, 1885. p.11.

18

MAESO, Justo. Loc. Cit.
Encerraban algunas de esas fórmulas que en las grandes crisis avasallan y regimentan los espíritus, fijando atrevidamente el derrotero de las revoluciones. La proclamación inmediata de la Independencia era una idea que satisfacía el anhelo de los pueblos, fatigados ya de aquellas tergiversaciones e imposturas sobre la fidelidad al trono de Fernando VII. La federación con su virtual corolario de gobierno propio en las localidades, despertaba a un mismo tiempo la embotada energía de los instintos populares y la adormecida ambición de los caudillos. Arrancar de Buenos Aires el asiento del gobierno general era una divisa de guerra que por aquel entonces condensaba todas las aspiraciones provinciales en pugna con el capitalismo porteño; y esa divisa ha perdurado más de medio siglo en los conflictos orgánicos de la nación argentina, hasta ser sustituida por otra, que parece definitiva y que el mismo Artigas habría preferido de buen grado: Buenos Aires deja de gobernar a la Nación y la Nación gobierna a Buenos Aires para poder gobernarse a sí misma. Y en aquellas Instrucciones estaba además claramente reclamada la igualdad de todas las provincias en las relaciones de comercio y de la navegación de los Ríos, planteándose de esta manera problemas económicos y sociales que han apasionado a los pueblos durante largos años y que esperaron la solución formulada en un campamento de 1813 hasta la caída de Rosas y la Constitución federal de 1853. ¡Con ese programa apareció Artigas en el escenario de las Provincias Unidas!. ${ }^{14}$

El Uruguay -no casualmente- daba sus primeros pasos hacia la modernización y, a medida que se afirmaba el Estado y su control sobre el territorio, aumentaba la necesidad de un relato de la nación y de un héroe referencial, coyuntura que enmarca la ruptura con la historiografía argentina en aras de constituir una historiografía nacional uruguaya. Esa labor requería un calendario patrio, el que comenzó a gestarse cuando, en 1884, se decretó duelo nacional en cada 23 de setiembre, día de la muerte de Artigas en Paraguay en el año 1850, a la vez que se publicaba por primera vez la partida de bautismo que confirmaba el 19 de junio de 1764 como su fecha de nacimiento y se instituia la celebración de su natalicio ${ }^{15}$, dotando al solo nacimiento de Artigas de un significado cuasi bíblico.

También en el año 1884, en una editorial para El Bien Público, Juan Zorrilla de San Martín perfilaba ya un Artigas que era "mucho más que un valiente", por ser "el vencedor generoso de Las Piedras; el que condujo al pueblo oriental en el éxodo semi sagrado; el que dictó las Instrucciones evangélicas del año 1813"16. Al año siguiente, Justo Maeso, en El General Artigas y su época. Apuntes documentados para la. Historia Oriental, hacia de las Instrucciones el documento que

atestigua que lejos de ser Artigas el caudillo feroz é ignorante que surgía á la vida pública sin más títulos que su lanza y su coraje, como lo han pretendido sus adversarios, fue el primer mandatario no solo del Río de la Plata, sino de toda la América Española, que proclamó en esas Instrucciones, desde su campamento militar, el gran decálogo de la organización política de las futuras repúblicas, y la base de los derechos del ciudadano sud-americano. ${ }^{17}$

Maeso realizaba en su libro un llamado de atención sobre el papel que jugaban en la Historia la multitud de papeles oficiales diseminados y perdidos en las guerras, olvidados en despachos, ignorados en los archivos de los Cabildos, en manos de particulares que obraban según sus intereses, documentos "extraviados, despedazados o perdidos" que podian ser gravitantes ${ }^{18}$. Esa sensibilidad para captar el peso de genuina hermenéutica en el oficio de historiar también se notó en la evaluación que hizo el propio Maeso de las Instrucciones. A juicio de José Pedro Barrán, él destacó "el carácter eminentemente concreto del federalismo proclamado por Artigas, 
BARRAN, José Pedro. Prólogo. In: MIRANDA Héctor. Las Instrucciones del año XIII. Montevideo: Biblioteca Artigas, Colección de Clásicos Uruguayos - vol.XLVI, tomo I, 1946. p.XVIII.

ZORRILLA DE SAN MARTíN, Juan. La Epopeya de Artigas. Montevideo: Colección de Clásicos Uruguayos - vol.XXXVIII, tomo II, 1963. p.148.

Cfr. CUADRO CAWEN, Inés. Las Instrucciones de año XIII y la democracia. In: CAETANO, Gerardo; RIBEIRO, Ana (coord.). Las Instrucciones del año XIII, doscientos años después. Montevideo: Planeta, 2013. p.107-131. lo que importaba e implicaba mucho más que la enunciación teórica de los principios federales", revelando una excepcional comprensión del pasado, a la que el erudito trabajo de Héctor Miranda no llegó19.

\section{4- La disputa ideológica y el calendario cívico}

Pero antes de esa labor de racionalización del discurso histórico de la nación que hizo Miranda, Zorrilla dotó de emocionalidad ese relato al presentar en 1910 su Epopeya de Artigas. En sus páginas el Congreso era ubicado en Peñarol y las Instrucciones adquirian una suerte de carácter supraterrenal, al ser catalogadas como "el milagro de aquel momento histórico". El mito de los orígenes alcanzó con Zorrilla su clave de bóveda, ya que en ese texto repleto de metáforas e imágenes poéticas de fuerte romanticismo se expuso en todos sus alcances la teoría de la predestinación nacional. La labor de Zorrilla, acorde con el personaje al que debía dar carnadura, fue definida por él como una misión, consistente en "profetizaros el pasado, y daros el ritual de nuestro culto cívico".

En el tomo V y final de su Epopeya, Juan Zorrilla de San Martín utilizó la imagen de Dante y Virgilio (que al pasar entre los muertos distinguian entre ellos a los vivos como aquellos que daban sombra), para afirmar que la triunfante democracia americana, "incipiente pero firmísima", no era sino "la proyección, sobre el suelo, de aquel hombre extraordinario que apareció en nuestra tierra, con un mensaje profético en los ojos, y que ahora, vivo en la región de las causas, vemos pasar a lo lejos, en medio de los inmortales, revelado y transfigurado por la luz" ${ }^{20}$. La democracia era la sombra y por lo tanto el signo de lo que permanecía vivo en Artigas; la democracia se había convertido en un concepto-meta, rebosante de expectativa. Elevada a esa región de idealidad y eternidad, la democracia legitimaba al héroe rescatado de la "leyenda negra", a la vez que este la consagraba a ella, al ser su mentor.

Tres años más tarde, las Instrucciones ingresaron definitivamente en el calendario patrio. Se cumplía su centenario y eso generó un movimiento especialmente significativo para la visualización del documento, dada la generación intelectual que estuvo detrás de los actos y homenajes programados. Un grupo de diputados presentó ante la Cámara de Representantes un proyecto de ley al que calificaron como un "homenaje justiciero al primero y más trascendental acto de los paises de la democracia rioplatense". Las Instrucciones, que "han servido de norma á las demás democracias de América", representaban tres ideas cardinales: libertad, democracia y república. La democracia, que no fue una voz frecuente en la documentación artiguista ni en la de la época (porque connotaba una versión arcaizante de la política y del gobierno, a la vez que era sinónimo de participación directa y tumultuaria del pueblo) ${ }^{21}$, de todos modos adquiría por una conceptualización retrospectiva ("retrolepsis") un lugar en el documento: tal como lo anunció Zorrilla, se había profetizado sobre el pasado. El resultado de la labor de Zorrilla puede verse también en toda la iconografía uruguaya, en la que la imagen de Artigas evolucionó desde el retrato del natural trazado por Alfredo Demersay (senil, enjuto y semicalvo), a figuras progresivamente más jóvenes y hercúleas que plasmaron en tela y bronce la apoteosis del culto al héroe.

Eduardo Acevedo publicó José Artigas. Su obra cívica. Alegato histórico casi al mismo tiempo que salía a luz la Epopeya de Zorrilla de San Martín. Luego comenzaría a publicar, en 1916, la serie de siete volúmenes 
ACEVEDO, Eduardo. Anales históricos del Uruguay. Montevideo: Barreiro y Ramos, 1933. t.I, p.264-265. de los Anales históricos del Uruguay, que comenzaban con un capítulo dedicado a "los tiempos heroicos" y la siguiente frase: "La historia del pueblo uruguayo arranca realmente de las invasiones inglesas". Lo peculiar en la defensa de Acevedo (porque un alegato es una pieza jurídica) no era el binomio de oposición colonia-independencia, sino la proyección americana que se le daba al héroe desde el relato de la nación. El recurso discursivo para lograr esa proyección consistió en señalar la excepcionalidad ideológica de Artigas, para convertirlo en factor indirecto del devenir independiente de todo el continente:

\footnotetext{
Suprimase a Artigas del escenario de la Revolución, en el período de 1811 a 1820 que es también el período de formación vigorosa de los pueblos del Río de la Plata, y las provincias argentinas habrian constituido lógica y naturalmente una monarquia, y no una monarquía autónoma, sino una monarquía tributaria de otras más fuertes que habrian reanudado con ligeras variantes el régimen del coloniaje español.
}

Acevedo condensaba la valía de Artigas en cinco logros cuya génesis remitía directamente a las Instrucciones de 1813: "apóstol de la idea republicana, contra la orientación monárquica de sus contemporáneos", Artigas fue "agente y propagandista incansable de la soberanía popular, contra la doctrina prevalente de las facultades omnímodas de los gobiernos"; un "promotor único de la organización de las Provincias del antiguo Virreinato del Río de la Plata sobre la base de instituciones federales perfectas, contra la absorbente oligarquía que desde la ciudad de Buenos Aires pretendia monopolizar todos los resortes gubernativos de las Provincias"; un "fundador de pueblos y de nacionalidades a base de legendarias altiveces de conducta y de incomparables sacrificios cívicos por el bienestar general permanente, contra la tendencia de sus contemporáneos a doblegarse a las tutelas extranjeras en holocausto a la tranquilidad del momento"; y "portaestandarte de las ideas de humanidad y de orden"22, en momentos además- en que la violencia recorría América.

El héroe había sido recortado del escenario rioplatense original, para convertirse en héroe nacional. Las Instrucciones habian perdido aquel contexto bélico, popular y de incertidumbre en el que las retrataban Acuña de Figueroa y la documentación de la época, para convertirse en un "decálogo sagrado", cada vez más significante en sí mismo, cada vez más cercano a las instituciones y los proyectos políticos del presente desde el que se las historiaba. Ese proceso de elevación de Artigas como "páter" que hacía de su territorio la "patria", era tan sacralizador, que se le adjudicaba dimensión americana, no porque se lo retratara en la región en la que efectivamente actuó en su momento, sino porque su excelencia y sus virtudes lo hacian trascender las fronteras de lo nacional. A las Instrucciones les esperaba un destino similar de fuerte proyección, por anticipación y capacidad profética. Algo que requirió estudios concentrados sobre su significado y valía.

En tal sentido, la obra más importante sobre las Instrucciones fue la de Héctor Miranda, obra escrita de cara a la tarea de nutrir el calendario y el relato de la nación. Miranda trabajó el tema siguiendo la línea argumental de A. D. Xenopol, que valoraba los "antecedentes" y utilizaba la cronología para establecer "series" de significado. Esto hacía desaparecer las complejidades y circunstancias aparentemente aisladas o particulares, en aras de una coherencia que tenía todos los elementos que la Historia conceptual les señala actualmente a los relatos de sentido teleológico: inevitabilidad, unidirección, causalidad sin espacio alguno para la casualidad. 
BARRAN, José Pedro. Op. Cit., p.XL.

VEDIA, Joaquín de. América. República Argentina. IBARRA Y RODRIGUEZ, Eduardo (Dir.). Colección Historia del Mundo en la Edad Moderna. Tomo XXIV. Buenos Aires: La Nación, 1913. p.243.

En el análisis de Miranda, las Instrucciones condensaban una época, adquiriendo resonancias superlativas que no provenían de la épica, como en el caso de Zorrilla, sino de la línea evolutiva, de ineluctable progreso, de las instituciones democrático-republicanas del Uruguay. Era el presente el que se imponía como ordenador de aquel pasado barroco de la revolución. José Pedro Barrán lo expresó con su claridad característica: Miranda "convirtió a Artigas en un constitucionalista y en un ferviente rousseauniano [...] olvidando a veces al caudillo auténtico y concreto, el que, sin duda, poseía una visión más lúcida del país que la que el historiador tuvo del caudillo"23. Lo convirtió, además, sin discusión, en el autor material e ideológico de las Instrucciones.

Mientras tanto, la historiografía argentina persistía en su visión sobre las Instrucciones y el feroz mandato que contenían. El mismo año en que H. Miranda publicaba su obra, en la Historia del Mundo en la Edad Moderna, publicada por la Universidad de Cambridge, en el tomo XXIV, dedicado a la Historia Argentina y escrito por Joaquín de Vedia, este describía así el proceso de elección de los diputados orientales que fueron portadores de las Instrucciones: Artigas

\footnotetext{
simplemente, fraguó una elección, nombrando, entre su gente, cinco individuos en representación de los pueblos de la comarca, cuyos diez individuos designaron á los que debian venir á la asamblea. Artigas, que se decía jefe de los orientales, proveyó á sus diputados de un diploma consistente en una simple carta de presentación, pues los procedimientos del fraude eran entonces muy sumarios. Además, el caudillo dio instrucciones terminantes á la representación oriental para que sostuviera en el congreso un programa que después ha venido á ser, si no una realidad positiva, por lo menos la fórmula fundamental del régimen federalista argentino. En una sola cosa, ese programa prematuro descubria el fondo de puro odio localista que lo inspirara á su autor: "que se opongan á que sea Buenos Aires la capital del estado». Naturalmente, la asamblea rechazó una diputación cuyos orígenes no podían ser más ilegales. ${ }^{24}$
}

En medio de una bifurcación historiográfica irreconciliable entre la historiografía uruguaya y la argentina, el pináculo de la elaboración del relato histórico del Uruguay llegó con Pablo Blanco Acevedo, quien, a pedido del Parlamento, escribió en 1922 su Centenario de la Independencia. Informe sobre la fecha de celebración, libro consagratorio del año 1825 como acta de nacimiento nacional. Lo complementó en 1929 con El gobierno colonial en el Uruguay y los orígenes de la nacionalidad, en el que volvió a ratificar su visión sobre un Artigas que no había sido "factótum" de la independencia, sino reflejo de un colectivo al que identificó con varias voces: pueblo, masa campesina, elementos democráticos. En la versión de Blanco Acevedo, frente a sus enemigos (Buenos Aires, Montevideo, Portugal) Artigas representó los intereses locales y salió victorioso aún en la derrota. Ese concepto (tan caro a una historiografía que llegaría luego a manifestar verdadero pudor de asociar la sola palabra 'derrota' al nombre de Artigas) le daba el triunfo moral al héroe que terminó por delinear el perfil nacional por la negativa: ni españoles ni porteños o provincianos, ni portugueses o brasileños. La tesis del "ni" avalaba el proyecto de unir la Provincia Oriental con las provincias argentinas y el Paraguay. El fracaso de esa segunda etapa del proyecto artiguista dejó victorioso al primero, por lo cual Acevedo afirmaba que la independencia oriental era una batalla inconclusa.

Esta interpretación, pináculo de la tesis independentista, se reflejó en una cronología patria que comenzaba el 12 de octubre de 1778 con la 
25

ASSUNÇAO, Fernando; PÉREZ, Wilfredo. Artigas Inauguración de su mausoleo y glosario de homenajes. Montevideo: Palacio Legislativo, Imprenta Rosgal, 1978. p.380-381.

26

ASSUNÇAO, Fernando; PÉREZ, Wilfredo. Op. Cit., p.391.

27

FALCAO ESPALTER, Mario. Formación histórica del Uruguay (1810-1825). Madrid: Espasa-Calpe, 1929. p.27. apertura del puerto de Montevideo al comercio internacional; proseguía con el Cabildo de 1806 que proclamara al gobernador Huidobro como autoridad platense; luego con la pionera Junta del año 1808; luego con el Cabildo de 1810 que negó reconocimiento a la Junta de Mayo; proseguía con el "pronunciamiento oriental" de 1811 en los campos de Asencio; llegaba a su máxima definición en abril de 1813, cuando los diputados orientales proclamaron "la Independencia y Soberanía de la Provincia" que contenian las Instrucciones; y culminaba, finalmente, con la declaración de "la Independencia Absoluta del territorio Oriental del Uruguay", el 25 de agosto de 1825.

Ese calendario de consensos hizo que Pablo Blanco Acevedo sostuviera que la mediación inglesa había sido importante para el nacimiento del Uruguay a la vida independiente, pero que el éxito del nuevo país había sido asegurado en realidad por Juan Antonio Lavalleja (jefe de la Cruzada del año 1825) y por Fructuoso Rivera (con su campaña militar de recuperación de las Misiones en 1828): la Historia incorporaba así a sus páginas la "trinidad" del panteón cívico nacional, representada por Artigas, Lavalleja y Rivera.

Sin embargo, en 1923, cuando se inauguró el imponente monumento a Artigas en medio de la plaza Independencia, apareció en la prensa un artículo muy crítico que hacía mención expresa a las Instrucciones, firmado por el Dr. Alberto Palomeque. Artigas, sostenía ese autor, quien nunca se propuso "independizar" a su provincia, fue fatal a las Provincias Unidas del Río de la Plata, "porque obligó á adoptar el camino que ni él mismo adoptó: el de la Independencia de 1828!". Para Palomeque, las Instrucciones y el proyecto de confederación contenian ideas e iniciativas propias de los filósofos e idealistas (que no le pertenecian a Artigas sino a su secretario Monterroso), pero a diferencia de quienes "siembran con ideas", la tarea del político y de los hombres de acción era conseguir lo concreto, "pretender lo que puede y no lo que quiere".

Héctor Miranda le salió al cruce defendiendo la idea de que Artigas era el real autor de las Instrucciones, pero por medio de una feliz adecuación: "el federalismo platense era [...] una simple adaptación del federalismo norteamericano", ya que "no hay nada caído de lo alto, no hay alumbramiento incomprensible". Miranda concluia de manera terminante: "Las Instrucciones son, en efecto, Artigas mismo", pues él "inscribió en su bandera el programa de las Instrucciones, fue su profeta armado, y lo hizo entrar á hierro y sangre en el dogma de la Revolución"25. Algo similar se dijo en el Diario del Plata, al elogiar el monumento recién inaugurado como "tributo de gratitud y admiración al genial visionario que echó las bases del decálogo político de la sociedad platense en las Instrucciones del año XIII y conquistó con brazo potente el primer triunfo resonante de las armas de la Revolución en la épica jornada del 18 de Mayo de 1811"26. Mario Falcao Espalter lo respaldó señalando que la autoría de las Instrucciones provenía del accionar político en el contexto, más que de la meditación libresca. "Artigas no era un teórico, sino un hombre de campo de gran inteligencia natural, conocedor de sus paisanos, así es que sus ideas encontraron en el sistema institucional de Estados Unidos la solución del problema político del Plata". Fue derrotado en 1820, pero -en otro claro caso de anacronismo-, Falcao afirmó que "este fermento federalista, esta terca resistencia al centralismo de Buenos Aires, quedaron latentes en el ánimo de los orientales y fueron uno de los gérmenes más eficaces de nuestra independencia"27. 
Las Instrucciones de Potosi se conocieron en 1916, al publicarlas en Buenos Aires monseñor Augusto Piaggio; eran de setiembre de 1813 y coincidian con las Instrucciones de los diputados orientales, de abril del mismo año 1813.

A propósito de los eventos de conmemoración de 1950 puede consultarse el detallado trabajo de DE LOS SANTOS FLORES, Claribel. La consagración mitica de Artigas: 1950. Homenajes y discursos a cien años de su muerte. Cultos, memorias e identidades. Montevideo: Tradinco, 2012 (Premio Anual de Literatura de 2011 en el rubro "HistoriaEnsayo inédito").
Esa estatua ecuestre erigida en Montevideo en medio de una plaza que llevaba el nombre Independencia y la construcción del Palacio Legislativo, inaugurado el 25 de agosto de 1925, monumento de mármol para la consagración del poder que garantizaba el equilibrio democrático finalmente alcanzado, fueron las grandes marcas urbanas de la síntesis histórica y de memoria colectiva celebradas por la Generación del Centenario. Era el culto del gran hombre, pero se procuraba "encarnarlo" en un entorno igualmente heroico, aunque colectivo. Con el mismo giro argumental, Falcao Espalter buscó diluir la influencia norteamericana en la imposición fáctica del contexto ("las ideas de Artigas, vividas por él en la campaña Oriental, encontraron en el sistema político de Estados Unidos la forma que les diera consistencia") y convirtió la autoría material de las Instrucciones en un dato secundario ("Las instrucciones de 1813, inspiradas por Artigas, probablemente no fueron redactadas por él, y esto demuestra que se trataba de un sistema, el federal, que estaba en el ambiente") ${ }^{28}$.

Luego resaltó la coincidencia entre las llamadas "Instrucciones de Potosí (Alto Perú)"29 y las Instrucciones de los diputados artiguistas, lo cual confimaba, en opinión de Falcao Espalter, la "plena popularidad del sistema artiguista, la afirmación democrática, republicana y federal como norma del porvenir político de América", pues mientras Moreno proponía un federalismo argentino que -según sus propias palabras- "difícilmente podrá aplicarse a toda la América", Artigas propuso un federalismo americano. La democracia representativa y la república como forma de gobierno (reflejo del presente de aquel Uruguay que consolidaba sus instituciones) convertían al proyecto federal de 1813 en proyecto político del continente. Era un proyecto valorado como "profético", pues en 1929 los Estados nacionales americanos ratificaban sus historias de predestinación, aunque todavía tuvieran pendientes algunas definiciones de fronteras.

¿Existían, de acuerdo con lo afirmado por Falcao Espalter, otros ejemplares de las Instrucciones, además de aquel que encontró Pelliza entre la papelería del Dr. Francia? Efectivamente, el celo documental que acompañó a la polémica en torno a Artigas, permitió descubrir y rescatar varias Instrucciones. La evolución de la propia Historia como disciplina se enlaza con esto: las publicaciones del Instituto Histórico y Geográfico del Uruguay creado en 1915; la aparición de los primeros centros de formación en Historia (la Facultad de Humanidades en 1947, el Instituto de Profesores Artigas en 1949); la consolidación y crecimiento de los repositorios documentales, especialmente del Museo Histórico Nacional, bajo la dirección de Juan Pivel Devoto, así como las publicaciones de documentos realizadas por el Archivo Artigas, desde su creación en 1944.

En la apoteosis del año 1950 pudieron converger un Uruguay satisfecho de sus instituciones y su democracia, con el centenario de la muerte del héroe, ya consagrado en forma unánime. Los múltiples festejos y conmemoraciones incidieron mucho en la imagen y el destino del documento Instrucciones. Por la ley № 11.473 se dispusieron diversas iniciativas orientadas a profundizar los trabajos de investigación histórica y las obras de representación plástica del héroe, del período y de sus principales hitos. Retratos, libros, esculturas: casi todo el material de exaltación patriótica escolar nació entonces ${ }^{30}$.

Nación, independencia y el uso del nombre del nuevo país, Uruguay, estaban aquejados de lo que la Historia Conceptual ha nominado "extra territorialidad y extra temporalidad": conceptos y nombres a los que se adju- 
ACEVEDO, Eduardo. Manual de Historia Uruguaya. Montevideo: Monteverde, 1942. p.9.

32

DEMICHELI, Alberto. Formación constitucional rioplatense. Montevideo: Barreiro y Ramos, 1955. Tomo I, p.31.

33

REVISTA NACIONAL. Montevideo, $2^{\circ}$ Ciclo, n.220, tomo IX, año IX, abril-junio de 1964. dicaban valores considerados como los únicos legítimos, a la vez que se los retro proyectaba como tales sobre el pasado. Estas formas de anacronismo también influyeron en la interpretación de las Instrucciones. El manual de Historia escrito por Eduardo Acevedo en 1942, por ejemplo, las calificó como "tipo insuperable de organización institucional que habría de servir de modelo a la Argentina y que aún hoy, a más de cien años de distancia, continúa siendo el eje de los más nobles movimientos de vida cívica en todo el antiguo dominio colonial"31. Era la afirmación del "sentimiento nacional" que debía unir a los uruguayos por encima de los enfrentamientos políticos y asimilar a los emigrantes que llegaban al pais en oleadas generosas.

En la obra de Alberto Demichelli, premiada por concurso del Consejo Directivo de la Facultad de Derecho y Ciencias Sociales en el año 1955, se ve claramente cómo la interpretación del documento puede hacer que este se anticipe a su tiempo e incluso salte las barreras de los Estados nacionales devenidos con posterioridad. De acuerdo con la visión de Demichelli, todos los principios que edificaron la gran Confederación Argentina estaban ya presentes en las Instrucciones; Artigas obró en ellas "con un profundo sentido profético que asombra y deslumbra", lo que las hacía vigentes y difíciles de superar:

\footnotetext{
Es algo así como una nueva legislación mosaica de los tiempos modernos, inspirada en principios que superan el momento histórico, amoldándose a toda posible exigencia del devenir. Si aquella se redujo a un dogma -la unidad y la soberanía de Dios-, esta proclama (lo hacía a) otro: la unidad republicana de la Confederación por obra de las soberanías parcializadas de las diversas partes constitutivas del Estado. Las Instrucciones orientales constituyen el Pentateuco político del Río de la Plata. Artigas habló en ellas entonces por la voz de los siglos. ${ }^{32}$
}

En ese clima ampliamente consagratorio, el Consejo Nacional de Gobierno resolvió declarar día de conmemoración cívica el 20 de noviembre de 1956, al cumplirse cien años de la inhumación de los restos de Artigas en Uruguay. En 1963, con miras al Bicentenario del nacimiento de Artigas que se celebraría al año siguiente, se proyectó (y luego se aprobó como ley) el traslado de los restos de Artigas, del Panteón Nacional a una cripta a construirse en el Palacio Legislativo ${ }^{33}$. Los homenajes se proponían recordar a Artigas mediante ceremonias que actualizaran "su ideario", expresión esta que se instaló definitivamente en los manuales educativos.

La ley 13.259 de mayo de 1964 destinó importantes sumas para facilitar la erección de monumentos a Artigas en diversas ciudades del interior de Uruguay; se expropió el predio donde estuvo su casa natal en Montevideo, se creó el Instituto Artiguista del Uruguay y se encargaron cuadros, medallas, concursos, estudios y publicaciones sobre el gran hombre y su época. El Instituto recibió una importante suma para iniciar la reproducción de obras artísticas relativas a los hechos patrios, destinadas a los centros de enseñanza del país.

Cuando la inestabilidad y confrontación política y social ganaron la realidad del pais, a partir de la década del sesenta, la figura de Artigas volvió a ser objeto de disputa en los relatos enfrentados y a ser demandado en forma perentoria como legitimador de los sectores en pugna. Sus restos incluso fueron trasladados, por temor a su posible robo (algo acaecido con la bandera de los Treinta y Tres Orientales, por parte del grupo guerrillero OPR 33). Producida la crisis institucional y el golpe de Estado, el gobierno de la dictadura promulgó, en setiembre de 1974, el decreto-ley 14.276 que 
ASSUNÇA0, Fernando; PÉREZ, Wilfredo. Op. Cit. p.99-100.

35

Ibidem, p.41.

36

Ibidem, p.562.

Ibidem, p.567. disponia la construcción de un mausoleo en la plaza Independencia, el que albergaría los restos de Artigas. Al año siguiente la exaltación-apropiación del héroe (recordado sobre todo en su condición de General) fue uno de los motivos y tópicos más reiterados en la auténtica "orgía historicista" que fue 1975 como Año de la Orientalidad.

Por su parte, el 19 de junio de 1977 se inauguró finalmente el Mausoleo a Artigas, al que Fernando Assunçao y Wilfredo Pérez dedicaron un libro, en cuya "Exégesis liminar" se señala: "El que nunca se fue, el que siempre estuvo, está y estará presente en la esencia misma de la orientalidad. Porque la tierra oriental, de la que nació, no es más que la sombra geográfica de su inmensa figura proyectada sobre el suelo americano. Porque él, como en el misterio evangélico, es hijo, esposo y padre de la Patria" ${ }^{34}$. En las páginas de este libro conmemorativo y celebratorio, las Instrucciones volvieron a ser, una vez más y aún en dictadura, el documento que revelaba más profundamente a Artigas "en toda su dimensión de estadista genial" 35 .

El discurso de inauguración del Mausoleo estuvo a cargo del teniente general Vadora, por entonces comandante en jefe del Ejército. Comenzó diciendo: "Nuestro Héroe fue, en principio, un soldado, por vocación personal y también por la vinculación que tuvieron sus antecesores con los quehaceres de milicias" ${ }^{\prime \prime}$. El gobierno civico-militar, desde un elegante nosotros, manifestaba tener "una irrenunciable obligación de proteger con fervor todo ese bagaje de superiores lecciones que nos dictara el Héroe, toda esa cultura propia que nos proporcionó la Independencia y el Nacionalismo de que ahora gozamos". Desde ese sitial de soldados de la causa que Artigas representaba, el significado político profundo de aquellos años más duros de la dictadura era sintetizado en esta pregunta que Vadora formuló en su discurso: "¿Cómo puede una doctrina extranjera, con exteriorizaciones seudointernacionalistas, pretender tener cabida en el seno de la gran familia oriental, si nuestras raices son artiguistas, son distintas y son nuestras? ${ }^{137}$.

No eran circunstancias oportunas por cierto para evocar la democracia. No casualmente el Mausoleo, contrariando el proyecto originario, fue decorado únicamente con las fechas de los hitos del ciclo artiguista, ya que no se pudo plasmar en sus paredes una sola frase que no se tornase sospechosa y hasta adversa, en esa disputa político-ideológica entre el Artigas-general y soldado enfrentado al Artigas caudillo agrario-revolucionario que había esgrimido la izquierda.

El nombre de Instrucciones del año XIII estaba esculpido en las paredes del Mausoleo y la clásica línea argumental que habian trazado Ramírez, Miranda, Maeso y tantos otros las vinculaba con los principios e ideas de la república y la democracia. ¿Qué podía decir al respecto un jerarca de la dictadura en semejante circunstancia? En su discurso, el teniente general Vadora lo resolvió Ilamando "actos de fe democrática" (nombre de uno de los documentos que por entonces se exigía a la población civil) a aquellos en que Artigas demostró "su pensamiento y acción", dejando en claro que

el objeto y fin del gobierno debe ser conservar la igualdad, libertad y seguridad de los ciudadanos y de los pueblos; que todo hombre es igual en presencia de la ley; que se asegure la confianza pública, que se respeten los derechos privados y que no se moleste ni persiga a nadie por sus opiniones particulares, siempre que los que profesan diferentes ideas a las nuestras no intenten perturbar el orden y envolvernos en nuevas revoluciones. ${ }^{38}$ 
39

La elección de las ocho frases artiguistas para incluir en el Mausoleo fue realizada por una Comisión Especial con representación de legisladores de todos los partidos, que fue creada específicamente para ello, tal como recomendara la Ley 17.310 de abril de 2001.

40

Disponivel em: <www.montevideo.com.uy>. Acesso en: 14 de agosto de 2009. Acesso en: 08 ago. 2013

41

MALAMUD, Carlos. Un balance de los bicentenarios latinoamericanos: de la euforia al ensimismamiento. In: MALAMUD, Carlos; STEINBERG, Federico; TEJEDOR, Concha (eds.). Anuario Iberoamericano 2011. Madrid: Real Instituto Elcano y Agencia Efe, 2011. p.339-341.

Respecto al primer caso, Tabanera aludia en forma directa a la acción de la "Comisión Nacional para la Conmemoración de los Bicentenarios de la Independencia de las Repúblicas Iberoamericanas" (creada el 4 de mayo bajo la presidencia de Felipe González); en relación con el segundo, la referencia directa era a los gobiernos boliviano, venezolano, colombiano y mexicano.
En el año 2009, en la recuperada democracia y bajo el primer gobierno frenteamplista de Tabaré Vázquez, cuando se quiso enmendar aquella imposibilidad de inscribir oraciones de Artigas en el Mausoleo, el Poder Legislativa votó - con consenso de todos los partidos con representación parlamentaria - ocho frases para incluir en las paredes del Mausoleo ${ }^{39}$. Una de ellas está tomada de la Oración Inaugural ("Mi autoridad emana de vosotros y ella cesa ante vuestra presencia soberana") y dos de ellas son artículos de las Instrucciones: la número dieciocho ("El despotismo militar será precisamente aniquilado con trabas constitucionales que aseguren inviolable la soberanía de los pueblos") y la número tres ("Se promoverá la libertad civil y religiosa en toda su extensión imaginable") ${ }^{40}$.

\section{5- Las conmemoraciones actuales}

El Bicentenario de las Instrucciones de 1813 se inscribe dentro de un proceso de conmemoraciones ya iniciado en el país y en la región bajo el signo de no pocos debates políticos e historiográficos. A título de ilustración, en un texto incluido en el Anuario Iberoamericano de 2011, el investigador para América Latina del Real Instituto Elcano, Carlos Malamud, advertía sobre el balance "limitado si no negativo" de los bicentenarios que varios gobiernos latinoamericanos ya habian realizado o estaban organizando para los años siguientes. En la fundamentación de su juicio sobre los "mediocres resultados" alcanzados por las celebraciones bicentenarias, Malamud destacaba algunas razones prioritarias: un "exceso de nacionalismo"; las "grandes diferencias políticas presentes en la región"; una "politización excesiva de las celebraciones", que en algunos casos implicaba "la exclusión de los discrepantes, tanto presentes como pretéritos"; el escaso presupuesto invertido; una "trivialización del concepto bicentenario"; un "bajo grado de conocimiento de las sociedades latinoamericanas acerca de la significación de los bicentenarios y sus implicaciones", etc. ${ }^{41}$.

Desde una perspectiva más académica, en el año 2010 la historiadora valenciana Nuria Tabanera García advertía que "el posicionamiento epistemológico del historiador ante los Bicentenarios se verá sin duda muy condicionado por los rasgos que caracterice la conmemoración en cada escenario y por la intensidad de los debates políticos e identitarios que se dibujen a su alrededor". En ese sentido, Tabanera alertaba sobre distintos peligros: la "intención abstracta de los gobiernos por conmemorar con una más o menos explícita intencionalidad política, que pretenderá tanto legitimar, justificar y fortalecer un discurso nacional de "argentinidad», "chilenidad", "mexicanidad", etc., que presuntamente goza ya de dos siglos de existencia, como dirigir o encauzar la "evaluación» sociocultural a que da pie el recuerdo de los mitos fundacionales"; la emergencia de "ciertos casos" en los que se buscará promover una "propaganda hispanista y de ocultación del encontronazo" o convertir a la "conmemoración ritual" en un "espacio en el que se tratan de consolidar visiones y revisiones de la historia, en pos, como en otros casos precedentes, de legitimar ciertos proyectos políticos"42.

Ante estos y otros desafíos, Tabanera apostaba a incentivar la reflexión de los historiadores "conocedores de los riesgos de los usos políticos de la historia", así como a evitar los caminos infértiles del "anacronismo, la teleología, el excepcionalismo o la banalización", a la hora de su previsible convocatoria "para avalar o ilustrar la conmemoración". Concluia con esta interpelación: "Quedaría por ver hasta qué punto los oídos de muchos 
TABANERA GARCÍA, Nuria. Pensar hoy e Bicentenario: sobre las dimensiones actuales de las revoluciones por la independencia de América latina. In: Amérique Latine Histoire et Mémoire, Les Cahiers ALHIM, 2010. Disponível em: <http:// alhim.revues.org/3425>. Acesso em: 27 jul. 2013

44

BREÑA, Roberto. El imperio de las circunstancias: las independencias hispanoamericanas y la revolución liberal española. Madrid: El Colegio de México-Marcial Pons, 2013. p.229, p.230 y p.233.

45

La lentitud fue tal que la iniciativa se inició en una legislatura y terminó de concretarse -con cambios significativos- en la otra. De ese modo, el proyecto de ley en su versión final debió suprimir "por estar ordenando una conducta hacia el pasado" uno de sus artículos, que hacia referencia expresa a la organización de actos y actividades en relación con el 25 de mayo de 2010. De todos modos, el texto final de la ley refirió a la planificación de actividades para el lustro 2010-2015. Cfr. "Versión taquigráfica de la sesión del 9 de junio de 2010" de la Comisión de Educación y Cultura de la Cámara de Senadores. "Celebración del Bicentenario del proceso de nuestra emancipación". Disponivel em <www. parlamento.gub.uy>. Acesso em: 05 ago. 2013

46

Cfr. Ley 18.677. Disponível em: <www.

parlamento.gub.uy>. Acesso em: 05 ago. 2013. La Comisión estaba integrada por representantes de seis ministerios (Educación y Cultura, Economía y Finanzas, Defensa Nacional, Relaciones Exteriores, Transporte y Obras Públicas, Turismo y Deporte), cuatro representantes del Poder Legislativo, uno del Poder Judicial, uno de la Universidad de la República y uno de las universidades privadas, uno del Consejo Directivo Central de la Administración Nacional de Educación Pública, un intendente delegado por el Congreso de Intendentes, los presidentes de la Academia Nacional de Letras y del Instituto Histórico y Geográfico del Uruguay, los directores del Museo Histórico Nacional, de la Biblioteca Nacional y del Archivo General de la Nación. responsables políticos y de muchos de sus conciudadanos latinoamericanos acogen unos aportes que ponen [...] en cuestión la base de los relatos nacionales dominantes"43.

Sobre el mismo particular, podría citarse también a Roberto Breña, historiador de El Colegio de México, quien en un texto reciente aborda la "incomodidad" de los historiadores frente a este tipo de instancias. "El primero es el carácter artificial y artificioso que tiene cualquier conmemoración [...]. El segundo aspecto es la tendencia de toda conmemoración a la "presentificación», no solo en el sentido de intentar darle al pasado un peso ingente sobre el presente, sino, sobre todo, de pretender que las "llaves» de los problemas del presente están en el pasado. [...] En tercer lugar, en el medio académico, las conmemoraciones dan pie a una cantidad tal de publicaciones, congresos y seminarios, que, inevitablemente, los saldos conmemorativos tienen que ser objeto de un análisis crítico que nos permita separar, por decirlo así, el grano de la paja". De todos modos, luego de advertir sobre las "simplificaciones históricas que conlleva toda celebración política" (que ejemplificaba en lo que señalaba como un excesivo énfasis acerca de "una modernidad o de un liberalismo gaditanos que fueron más complejos y matizados"), Breña prevenía también acerca del "lamento académico por el nacionalismo exacerbado" en este tipo de instancias. "Si los políticos no pueden sino hacer lo que [...] "está en su naturaleza», cabe esperar lo mismo de los académicos (nos referimos a la veta crítica que debería siempre caracterizarlos). A este respecto, sin embargo, el pronóstico es más difícil, pues en no pocos casos las conmemoraciones académicas han sido más «celebraciones» que eventos que lleven a sus participantes y a sus auditorios a revisar críticamente lo acontecido en la región entre 1808 y $1830^{\prime 4}$.

Uruguay no ha constituido una excepción a este clima de controversias. Luego de un arduo, debatido y lento trámite parlamentario iniciado en julio de 2009 y concluido el 4 de agosto de $2010^{45}$, el Parlamento aprobó la Ley NN 18.677, titulada Año de celebración del Bicentenario del proceso de emancipación oriental, la que fue promulgada por el Poder Ejecutivo el 13 de agosto del mismo año. Por el artículo $1^{\circ}$ de esta ley se declaró "el año 2011 como año de "Celebración del Bicentenario del Proceso de Emancipación Oriental», en el marco de la lucha de los pueblos americanos por su autodeterminación e independencia, reconociendo la participación central de la figura de José Artigas en la misma".

Por su artículo $2^{\circ}$ se creó una "comisión interinstitucional" denominada Comisión del Bicentenario de la Revolución de Independencia del Río de la Plata 2010-2015, que tendría

por cometido la planificación, para los años 2010 a 2015, de las actividades de conmemoración y celebración de los principales hechos históricos del proceso revolucionario e independentista, en la etapa comprendida entre 1810, inicio de la Revolución en el Río de la Plata, y 1815, año de la mayor expansión del proyecto impulsado por José Artigas en la Provincia Oriental y en el Sistema de los Pueblos Libres. ${ }^{46}$

Ciertas ambigüedades del texto de ley finalmente aprobado tienen que ver con uno de los principales motivos de discusión: la resistencia, por parte del gobierno y de legisladores de todos los partidos, en reconocer la fecha del 25 de mayo de 1810 como el inicio del proceso emancipador oriental. Ello llevó a una compleja transacción por la que, si bien se fijó 
47

También en este proceso debe señalarse la propuesta presentada a la Comisión de Educación y Cultura del Senado en octubre de 2005 por el entonces senador y expresidente de la República, Dr. Julio Maria Sanguinetti. En esa iniciativa, con el título de Un necesario debate, Sanguinetti proponía un cambio significativo en el calendario cívico uruguayo: "declarar el 5 de abril -o el 13 si se prefiere- Día de la Nacionalidad y celebrarlo como fecha mayor de nuestro proceso histórico, en homenaje a Artigas y reconocimiento al valor ya configurado de una "nacionalidad orientalı". Por su parte, el 25 de agosto se celebraría el "Día de la Declaración de la Florida", "como homenaje a ese acto de libertad frente a Brasil y Portugal pero sin asumirlo como fecha singular de "la» independencia". Esta iniciativa no prosperó en el Parlamento pero generó un debate profundo en el que participaron historiadores y legisladores.

48

"Restauraciones. Motivo de fiesta. Se gastarán cinco millones de dólares y proyectan un edificio del Bicentenario por otros cinco millones. Pero el MEC admite que la "reflexión histórica» no Ilegó a la gente". SUPLEMENTO 'Qué pasa'. El País, Montevideo, 8 de octubre de 2011. finalmente el 2011 como el año de Celebración del Bicentenario del Proceso de Emancipación Oriental, se creó la "comisión interinstitucional" antes referida con la curiosa denominación de Comisión del Bicentenario de la Revolución de Independencia del Río de la Plata 2010-2015, prolongándose el calendario de eventos para todo el lustro, aunque con la instancia crucial del 25 de mayo de 2010 ya transcurrido al aprobarse de manera efectiva la ley ${ }^{47}$.

Durante el año 2011, la Comisión y el propio gobierno impulsaron las celebraciones, que tuvieron como epicentro popular los espectáculos musicales realizados en cuatro escenarios del centro de Montevideo, el día 10 de octubre y en conmemoración de los doscientos años de la asamblea oriental de la "Quinta de la Paraguaya" (de esa misma fecha pero de 1811), en la que Artigas fue proclamado "Jefe de los Orientales". Esta fiesta tuvo sin duda una fuerte presencia popular, aunque -como los propios organizadores lo reconocieron- no logró promover una reflexión ciudadana sobre los significados de la celebración.

Así narraba el evento y las interpretaciones sobre su significación más profunda el suplemento Qué pasa del diario El País:

A unos pasos de las oficinas del Bicentenario está el despacho del director general de secretaría (del Ministerio de Educación y Cultura), Pablo Álvarez, uno de los responsables políticos de los festejos. Mate en mano, el jerarca reconoce que no se ha logrado uno de los objetivos planteados: provocar en la mayoría de los uruguayos una «reflexión histórica».[...] «Para nosotros, habilitar esa reflexión era mucho más importante que cualquier espectáculo artístico», dice el director. "La idea era desenfocar esa reflexión de los espacios exclusivamente académicos y repensar la historia porque siempre hay una línea de continuidad entre lo que sucedió y lo que hoy está sucediendo». Pero esa reflexión no se ha producido. "Lamentablemente la gente no tiene mucha idea; no se ha consustanciado con ese debate, es evidenten, dice Álvarez, de 33 años. Pero agrega que el problema va más allá del tono que se le dio a la celebración, donde los espectáculos musicales tienen un lugar central. "Muy pocos programas de televisión están vinculados a la historia. Vivimos en una sociedad que no debate estas cosas. ¿Cuán importante puede ser para dos vecinos si está bien o no el 2011?». El senador blanco Gustavo Penadés, quien también integra la comisión, piensa que se desaprovechó una oportunidad de "fomentar la revalorización histórica de Artigas y el aprendizaje popular de lo que se conmemora". $Y$ dice que influye el sentido vergonzante de la izquierda, "de no revalorizar los hechos históricosm. ${ }^{48}$

La celebración y la fiesta popular se imponían finalmente a la conmemoración histórica. Parte representativa de una historia que, con seguridad, no ha terminado. 